\title{
Pronouns in English and Arabic: A Contrastive Study
}

\author{
Zainab Kadim Igaab ${ }^{1} \&$ Intisar Raham Tarrad ${ }^{1}$ \\ ${ }^{1}$ Department of English, College of Education for Humanities, University of Thiqar, Iraq \\ Correspondence: Zainab Kadim Igaab, Department of English, College of Education for Humanities, University \\ of Thiqar, Iraq. E-mail: zainabigaab@yahoo.com
}

Received: October 4, 2018 Accepted: November 1, 2018 Online Published: January 28, 2019

doi:10.5539/ells.v9n1p53 URL: https://doi.org/10.5539/ells.v9n1p53

\begin{abstract}
Pronouns are defined as being one of the parts of speech that obtain their meaning from other noun phrases in a sentence. This study is descriptive, analytic, and contrastive. It deals with comparing pronouns in English and Arabic by concentrating on the points of difference and similarity between the two languages.

This study aims at describing pronouns in both languages and then the comparison is made by defining pronouns, showing their syntactic, semantic, and pragmatic aspects to know to what extent both languages are similar or different in using pronouns.

It is hypothesized that the two languages are similar to each other in terms of their syntactic, semantic, and pragmatic aspects of pronouns; pronouns are found in both languages; and there are some points of similarity and difference between the two languages, but the differences outweigh the similarities.

English has a clear division of pronouns. Pronouns are dealt with syntactically, semantically and pragmatically. In Arabic the division of pronouns is completely different.
\end{abstract}

Keywords: contrastive analysis, syntax, pronouns

\section{Introduction}

The present study deals with pronouns as lexical items which substitute the noun phrases in the sentence or in the larger discourse. Pronouns are significant for avoiding repetition and they are used as a way of economy of the expression in the language. This study deals with the topic of pronouns in terms of three aspects syntactically, semantically, and pragmatically. It is not an easy task to give a comprehensive explanation which includes all those aspects of pronouns in English and Arabic.

There is a difficulty in describing pronouns syntactically, semantically and pragmatically in Arabic because the types of pronouns which are dealt with syntactically are different from those which are dealt with semantically and pragmatically. So, this study is responsible for filling the gab between the two languages in terms of pronouns.

The syntactic, semantic, and pragmatic aspects of pronouns are dealt with in English and Arabic, but in a different style. In English, pronouns are studied explicitly while in Arabic, pronouns are studied according to a certain division.

As a phenomenon, the reflexive pronoun is found in Arabic grammar, but it lacks a specific title and definition. This causes a problem for the researchers, because they want to study reflexive pronouns from the Arabic point of view without depending on the English point of view. Concerning the Arabic pronouns, there are certain types of pronouns that are not classified distinctly whether they belong to the syntactic or the semantic and pragmatic aspects of pronouns.

To the best of the researcher's knowledge, the points of similarity and difference between the two languages are not shown in any other study in order to compare and contrast pronouns in English and Arabic.

\section{Relevant Scholarship}

\subsection{Definitions of Pronouns in English and Arabic}

In English, pronouns can be defined as lexical items. They belong to closed system items. The meaning of the word pronoun comes from pro and noun that means the possibility of using the pronouns instead of nouns (Arts, 2001, p. 30). 
They can get their meaning from the noun phrases for which they substitute. Pronouns rely on syntax and context for their interpretation (Rodman \& Hyams, 2007, p. 200).

A pronoun takes its meaning from the meaning of the noun phrase which is stated previously. This noun phrase is called the antecedent. There must be clarity in the use of an antecedent. It means that the relationship between the pronoun and its antecedent must be plain (Greenbaum \& Nelson, 2002, p. 178).

In Arabic, pronouns (Dhama?ir) are defined as one type of definiteness. They are indeclinable (mabniyya). It implies that they do not change their form. They are not derived nouns because they do not have dual and plural forms. They are considered as one type of metonymy (al-kinaya) but they are not the metonymy itself. Pronouns are used to refer to the first, second, and third persons. They are used to replace an explicit noun. That's why, they are considered as a way of economy (Al-SuyoTy, 2001, p. 194; Al-9alawy, 1992, p. 516).

Using a pronoun stipulates that the speaker and the addressee know its reference. It means that a speaker uses a pronoun only after knowing that the addressee knows to what it refers either to the speaker, the addressee, or a person who is absent. Pronouns are found in each language. Although pronouns are small in size but they are considered as structured expressions which are put for the purpose of avoiding repetition and confusion (Aniis, 1994, p. 290).

\subsection{Syntactic Aspect of Pronouns in English and Arabic}

In English, syntactically speaking, pronouns function like a noun phrase. In a limited way, they are connected with determiners and modifiers. Although, they substitute a noun phrase, they do not accept all the rules that are applied on. The pronouns cannot be preceded by determiners. This is because they have their own determiners. It is correct to say the men, but the they is incorrect (Quirk et al., 1985, p. 335).

Because the pronoun is considered as a substitution of a noun phrase, there is a relationship between the pronoun and the noun phrase. The reference of the pronoun is variable. It depends on the context of situation in which the pronoun is used (Kroeger, 2005, pp. 135-136).

A pronoun can occupy the positions of a subject, an object, and an object of a preposition. The pronoun must be equal to the noun phrase in terms of case subjective, objective, and possessive, person personal and non-personal, number singular and plural, and finally in terms of gender feminine and masculine (Kroeger, 2005, p. 46; Leech \& Svartvik, 2002, p. 355).

While in Arabic, for each pronoun there must be an explicit noun which is considered as a way of getting rid of ambiguity. That's why: a pronoun has a strong connection with the explicit noun phrase (Ibn-Faris, 1971, p. 504).

There are certain rules which join the pronoun with the explicit noun:

a) In terms of number, a pronoun and the explicit noun must have the same number singular, dual, and plural.

b) The position of the explicit noun is before the pronoun to give an explanation for the goal of using the pronoun.

c) They must also agree in gender in terms of feminine and masculine (Al-LaHyany, 2002, p. 9).

\subsubsection{Types of Pronouns in English}

In English, the pronouns are eight in number, but they are seven if the possessive pronouns are placed within personal and reflexive pronouns under the title central pronouns.

\subsubsection{Personal Pronouns}

Personal pronouns are of three types. The pronouns that refer to the speaker $I$ and we are called the first person; the pronouns that are used to refer to the addressee or the person is speaking to you are called the second person pronouns; and the pronouns he, she, it, and they are used to refer to the person or thing who/which is absent which are called the third person (Kimball, 2010, p. 98; Azar et al., 2001, p. 38).

The personal pronouns must match their antecedents in terms of case, person, number, and gender. This process is called agreement. The personal pronouns are used to replace the whole noun phrase.

1) I read a book. It was good.

2) I read some books. They were good.

3) I like tea. Do you like tea too? (Azar et al., 2001, p. 38)

There is a type of nouns which is called generic. It refers to any certain group in general which does not refer to 
a specific person or thing such as a student. For this reason, a singular masculine pronoun is used but many speakers tend to use both feminine and masculine pronouns to replace a noun phrase. In order to solve this problem, a plural pronoun is used.

4) A student should always do his assignment.

5) A student should always do his/her assignment.

6) Students should always do their assignment (Azar, 2000, p. 39).

Another kind of nouns is called a collective noun like family that is used to refer to a group of things, persons, or a single unit. In this case, a singular neutral pronoun is used if the collective noun refers to impersonal single unit. But the plural pronoun is used if the collective noun refers to members or individuals in the group to which it refers.

7) My family is large. It is composed of nine members.

8) My family is loving and supportive. They are always ready to help me (ibid, p. 39).

Personal pronouns are divided in terms of singularity and plurality. The singular pronouns are $I$, he, she, and it and the plural pronouns are we, you, and they. They are also divided in terms of gender in which first and second person pronouns do not have gender distinctions. It means that the pronouns $I$, we, you are used whether the speaker is feminine or masculine whereas third person singular pronouns have gender distinctions. The pronoun he refers to male; the pronoun she refers to female; the pronoun it is used to indicate neither male nor female which is called neutral; and the pronoun they is used to indicate either male or female. Concerning case, the personal pronouns have three cases. The pronouns $I$, we, you, he, she, it, they are the pronouns of the subjective case as well as in the objective case, they are me, us, him, his, her, it, them, and you (Silva, 1998, p. 13).

There are errors concerning the use of the subjective, objective and possessive cases. The correct use must be as the following:

a) In a compound subject, a pronoun should be used in its subjective case.

9) Betty and I watched the Olympics on television.

b) In the case of the verb to be, the subjective case of a pronoun is used.

10) It is she. The winner was I.

c) If the pronoun occurs as a subject of a sentence, then a subjective case will be used.

11) We travelled by plane.

d) When the pronoun occurs as an object, an objective case is used.

12) David gave me a present.

e) If there is a preposition, it will be followed by an objective pronoun.

13) He is not coming with us.

f) The subjective pronoun is used in elliptical clauses. There are certain words that are unexpressed in these clauses. These words take the subject position.

14) You are better than he.

g) Neither the objective nor the subjective pronouns are used with gerunds, but the possessive pronouns are used.

15) We have always regretted her leaving for California (Nelson, 2001, p. 59; Obrecht, 1999, p. 25).

\subsubsection{Reflexive Pronouns}

A reflexive construction means that the subject and the object of the sentence refer to the same person. There are two groups which are singular and plural. The singular reflexive pronouns are myself, himself, herself, yourself and the plural ones are yourselves, themselves, and ourselves. The reflexive pronoun yourself can be singular and plural. The reflexive pronouns have a syntactic function as an object of a verb or a preposition when the object and the subject indicate the same person.

16) I saw myself in the mirror (Eastwood, 1994, p. 233).

\subsubsection{Possessive Pronouns}

Possessive pronouns are divided into two groups. The first is called possessive determiners my, our, their, her, his, its, and your, which are used to modify a noun. They cannot be used alone. The second is called the 
possessive pronouns mine, ours, yours, theirs, his, its and hers, which are used alone. There is a connection between the possessive pronouns and the possessor not the thing possessed. They must agree with the possessor in number and gender.

17) The boy lost his book.

The girl lost her book (Greenbaum \& Nelson, 2002, p. 101).

The number of the thing possessed whether singular or plural does not make a difference in the form of the possessive pronoun and the possessive adjective.

18) The boy lost his book.

The boy lost his books (Eckersely, 1966, p. 26).

The possessive pronoun is used to refer to the parts of the body, personal belongings and other expressions.

19) Mary has broken her leg. (parts of the body)

20) They have changed their minds again! (personal belongings)

21) Don't lose your balance! (in other expressions)

The definite article is used instead of the possessive pronouns that are used in prepositional phrases related to the object or in passive constructions related to the subject.

22) She took me by the hand.

23) I must have been hit on the head with a hammer (Quirk \& Greenbaum, 1973, p. 105).

The possessive adjectives are also called independent possessive because they do not rely on a noun in their occurrence and the independent pronoun can be used after a preposition. In this case, a double genitive is constructed.

24) I have been talking to a friend of yours (one of your friends) (Alexander, 1990, p. 60; Quirk et al., 1985, pp. 362-363).

\subsubsection{Reciprocal Pronouns}

Two main reciprocal pronouns are found which are each other and one another. They have also a genitive form as each other's and one another's and the only difference between them is that each other refers to two only and one another refers to more than two (Jesperson, 2006, p. 79; Greenbaum \& Nelson, 2002, p. 103).

\subsubsection{Demonstrative Pronouns}

A group of words are called demonstrative pronouns which are this, that, these, those, here, there, now. They are used either to refer to place or to time. The place and the time are either near or far away from the speaker. In writing, they have an antecedent in order to know to what they refer. The antecedent noun may be after or before the demonstrative pronouns.

25) This is my answer.

In speech, there is no antecedent, because their use will be explained in terms of the context of situation in which they occur. That's why, their reference will be clear.

26) I'll take these (Radford, 2004, p. 447; Gucker, 1966, p. 53).

The demonstrative pronouns can be divided in terms of number. The singular demonstrative pronouns are this, and that and the plural ones are these and those. Other demonstrative pronouns are the former, the latter, and such. The latter and the former are used to refer to the first of two or the second of two.

27) Shakespeare and Goethe were both great poets; the former was an English man, the latter a German (Eckersely, 1966, p. 27).

The singular demonstrative pronouns this and that are used with count and non-count nouns. The singular and plural ones are used to replace a whole noun phrase or they may be followed by the pronoun one(s) to take the place of the noun that they substitute.

28) The chair is more comfortable than that one.

29) Those apples are sweeter than these ones (Quirk et al., 1985, p. 372).

The demonstrative pronoun that can be used to represent either a previously mentioned state or an action.

30) Her face was now sadly different from that which we used to admire at home (state). 
31) Did he work in the fields? Yes, he did that occasionally (action) (Jesperson, 2006, p. 117).

\subsubsection{Interrogative Pronouns}

The main function of the interrogative pronouns is to ask questions, which are who, whom, which, what, whose and that. The pronouns who, whose and whom are used for persons. The pronoun whom is used in the objective case, that is more formal than who. The genitive form of who is whose. There are other interrogative pronouns which are which, that and what. The pronouns which and what have no case distinctions. It means that they have the same form either in the subjective or objective position. The pronoun which can be used for personal and impersonal nouns while what is used only with impersonal nouns (Borjars \& Burridge, 2010, pp. 56-57).

\subsubsection{Relative Pronouns}

The relative pronouns always occupy the beginning of the relative clause which is used to modify the antecedent word of the main clause. The relative clause is also called the adjective clause because it works like an adjective which is used to modify a noun. The relative clause comes after the antecedent noun which modifies it (Greenbaum \& Nelson, 2002, p. 104).

The relative pronouns have distinctions in gender feminine, masculine; case subjective, objective, and possessive; person personal and non-personal. The relative pronouns who, whom, and whose are used with personal nouns. The pronoun who occurs in a subject and an object position and the pronoun whom is used formally in an object position. The pronoun whose is the possessive form of who.

The non-personal pronouns are what, which, whose and that. The relative pronoun that which is called neutral gender may be deleted in certain sentences. In that case, it will be called zero that clause.

The house which (or that or zero) we bought....... (ibid, p. 104).

The positions that are filled with relative pronouns are subject, object, complement and object of a preposition.

32) The man who arrived at the school was a painter. (subject)

33) I rang the teacher who is in charge of a library. (object)

34) That was the man who(m) I saw at the school. (complement)

35) The man to whom he shouted ran to help him. (object of a preposition)

In certain cases, the relative pronoun may be deleted from the relative clause. There are three types of reduction:

a) The relative pronoun is deleted in the restrictive relative clause if it occurs as a subject.

b) If the relative clause contains a non-finite verb, the relative pronoun is deleted.

c) The reduction process also occurs when the relative clause is verbless and has the function of the prepositional phrase post-modifiers (Kennedey, 2003, p. 282).

\subsubsection{Indefinite Pronouns}

In terms of the morphological and the syntactic behavior, the indefinite pronouns are divided into two groups. The first group includes indefinite pronouns which have a determiner morpheme such as every, some, any, no and the nominal morpheme as body, thing, and one. The second group contains the indefinite pronouns which have the partitive of-phrase.

The compound pronouns are of four types:

1) Universal compound pronouns are everyone, everything, each, every, both and all.

2) Assertive compound pronouns are somebody, someone, something, multal and paucal qualifiers, one, half, several, enough, other and another

3) Non-assertive compound pronouns are anyone, anybody, anything, and either.

4) Negative compound pronouns are no one, nothing, nobody, neither, and none. Every pronoun ends in one is personal while those ending in thing are non-personal. The indefinite pronouns can be followed by either a relative clause or a prepositional phrase, which cannot be preceded but followed by an adjective (Biber, 1999, pp. 99-101; Quirk et al., 1985, pp. 376-377).

\subsubsection{Types of Pronouns in Arabic}

\subsubsection{Occurrence}

Concerning the occurrence of pronouns, they are divided into explicit (al-Dhahira) and implicit (al-mustatira). The explicit pronouns consist of three types which are attached (al-mutaSila), detached (al-munfaSila) and 
reflexive (al-?ishariyat).

\subsection{Explicit}

Explicit pronouns exist in the words which can be pronounced and written. They are divided into attached, detached and reflexive. It is important to know that the word with which they are used is called agent. If a pronoun attaches to its appropriate agent, it is called an attached pronoun. They are written as one word. If the pronoun is separated from its agent, it is called a detached pronoun (Al-Ghuriny, 2000, p. 66).

\section{i. Attached Pronouns}

The attached pronoun appears at the end of the word which cannot be used separately at the beginning of the sentence and cannot occur after (illa). It can be used with verbs (ibtasamtu) (I smiled), nouns (baytuka) (your house), and prepositions (ilayka) (for you).

In terms of parsing, the attached pronouns are divided into:

1) Pronouns that are used in the nominative case:

a. The pronoun (alif al?ithnayn) (alif of duality) which is used with the present, past, and command verbs.

36) (?inDhra) look at something.

37) (Sana9a) They made something.

38) (lam yaktubaa) They did not write (Al-Mashharawy, 2012, pp. 6-7).

b) Movable feminine taa? which relies on the (Haraka) at the end of it. It is either (Dhamma) when it refers to the speaker (darastu ana) (I studied), or (fatHa) as (darasta anta) (you studied) when it refers to the addressee.

c) Femininity nuun is also used with past, present, and command verbs:

39) (yudrusna)-They are studying.

40) (?inhaDhna)-Wake up.

41) (darasna)-They studied.

d) Second person feminine yaa? that is used with the present and command verbs only:

42) ?iktubi- Write.

43) lam ta9lami-You did not know.

e) na.

44) darasna alkitab-We studied the book.

f) waw of plurality which is connected with the past, present, and command verbs:

45) (9amalu) They worked.

46) (?drusu)-Study.

47) (yaktubuun) They are writing (Al-Farakh, pp. 44-46).

2) Pronouns that are used in the accusative and the prepositional cases are: (a) First person yaa? (b) Second person kaaf (c) Third person haa? and (d) na

These pronouns depend on the (Haraka) above the word (Ibn-Jinny, 1985, pp. 160-161).

\section{ii. Detached Pronouns}

Detached pronouns do not attach to any word which occurs as a full word with its own meaning. They are twenty four pronouns in number which are divided in terms of parsing into nominative and accusative.

1) The nominative pronouns are twelve in number that are (anta), (anti), (antum), (antuma), (antunna), (huwa), (hiya), (huma), (hum), (hunna), (ana), and (naHnu) (Ibn-Aldahan, 1988, p. 49).

2) The pronoun that occurs in the accusative case is (iyy). It includes twelve pronouns which are (iyyay), (iyyaka), (iyyaki), (iyyana), (iyyakuma), (iyyakum), (iyyakunna), (iyyahu), (iyyaha), (iyyahuma), (iyyahum), and (iyyahunna) (Ibn-Jinny, 1985, p. 160).

But they are not used in the prepositional case. The purpose beyond its use is conciseness. The attached pronouns are considered as briefer than the detached ones. That's why, the attached pronouns are preferred to be used than the detached ones (Al-Anbary, 1982, p. 383). 


\section{iii. Reflexive Pronouns}

A reflexive pronoun exists in the language without a specific definition or title to refer to. This is considered as a problem for Arab researchers. That's why; they borrowed the term reflexivity from other languages such as English. The reflexive construction can be found when the subject and object exist in the same sentence and refer to the same person. This happens only with inversion verbs which are (Dhanna), (Hasiba), (khala), (za9ima), (wajada), (9adima), (faqad), except using the word (nafs) (the same). The reflexive pronouns occur in the accusative and the prepositional cases, but not in the nominative case (Al-Ra9iiny, 1990, p. 310; Al-Quuzy, 1981, pp. 126-127).

\subsection{Implicit Pronouns}

The implicit pronouns are not used in speech and in writing. The detached pronouns are used to refer to them. For example, in the past verb one can say that it is a past verb and its subject is an optionally implicit pronoun. It means that, the detached pronouns denote the implicit pronouns which have their own rule like the other pronouns. They occur in the subject position. That's why; they are always in the nominative case. The implicit pronoun cannot be called the deleted pronoun because it exists even if it does not occur in speech or in writing, which is divided into optionally and obligatory (Ibn-9aqiil, 1997, p. 95).

The implicit pronoun is used with the verbs. For each verb, there must be a subject. The verb refers to an action and the subject is the doer of that action. Therefore, the subject is the main part of the sentence which can be implicit, but not deleted. The object is considered as redundant which can be omitted from the sentence and does not affect the structure of the sentence (Al-Sa9ady, 2009, pp. 9-10).

The implicit pronoun is used to refer to the three types of personal pronouns which are the first, second, and third. It is obligatory with the first and second while optional with the third. The Implicit pronoun depends on the tense of the verb, which is different from one verb into another:

a) In the past verb, the optionally implicit pronouns are (huwa and hiya);

b) In the present verb, the implicit pronoun relies on the sound with which the verb starts;

c) In the command verbs, the implicit pronoun is (anta) (Al-Farakh, pp. 51-53).

The difference between optional and obligatory implicit pronouns is that the former can be replaced by an explicit noun while the latter cannot. There are certain positions in which the obligatory implicit pronoun is used:

a) if it is a subject of a command verb which is used for singular masculine second person;

b) the subject of a present verb which starts with a singular second person taa?;

c) the subject of a present verb starting with hamza;

d) the subject of the past verbs which are used for exception like (khala), (9ada), (Hasha);

e) the exclamatory past verb with a subject which must be obligatory;

f) the verbal noun of the present or command verb;

g) occurring when there is a participle which substitutes a command verb (Ibn-Ya9iish, 2001, p. 109).

The positions for which the optionally implicit pronoun is used are:

a) when it can be replaced by an explicit noun;

b) when it can be explicit with the verbal noun of the past verb, an adjective, and an adverb (Al-SuyoTy, 2001, pp. 244-245).

\subsubsection{Division of Pronouns in Terms of Type}

Each pronoun must either refer to feminine or masculine in order to have agreement with the explicit noun or with the verb. The first person pronouns do not have gender distinctions because the speaker who uses the pronouns (ana) and (naHnu) can either be feminine or masculine. Gender appears in the second and third person pronouns. The second pronouns which refer to feminine are (anti), (antunna), and (kaf) while the masculine second person pronouns are (anta), (antum), (kaaf). The third person pronouns which indicate feminine are (hiya), (hunna), and (haa?) whereas the masculine third person pronouns are (hum), (huwa) and (haa?). The pronoun (huma) can be used to refer to either feminine or masculine (Ibn-9qiil, 1997, p. 82).

\subsubsection{Division of Pronouns in Terms of Number}

Pronouns are divided in terms of number into singular, dual, and plural (Warith \& Mursy, 2013, pp. 29-30). 


\subsection{Semantic and Pragmatic Aspects of Pronouns in English and Arabic}

This section will deal with the meaning and usage of each pronoun.

\subsubsection{Types of Pronouns in English}

Pronouns are eight in number.

\subsubsection{Personal Pronouns}

Halliday and Hasan (1976, pp. 31-32) show that the personal pronouns have a specific reference. The term reference can be used within semantics and pragmatics. Within semantics, reference is the semantic property of definiteness and specificity while in pragmatics, the reference of the pronouns depends on the context of situation in which the pronouns are used. It means that there is a relationship between the pronouns and the context. The situational reference is within pragmatics.

There are personal pronouns that can be used impersonally. The pronoun you is used not to refer to the addressee, but to the speaker. Also, the pronoun we is used to refer to the speaker. It means that it is used to indicate a single person rather than two or many speakers. The pronoun we can be used to give a generic meaning. The personal pronoun they may not have an explicit antecedent which may be implied (ibid, pp. 31-32).

\subsubsection{Reflexive Pronouns}

Reflexive pronouns carry the meaning of reflexivity, which refer to a specific person or thing. The meaning of reflexivity is expressed when the subject and object refer to the same person (Givon, 1990, p. 628).

The reflexive pronouns have another function. They are used as emphasizing pronouns, that is, they focus that this action is done by that person and nobody else. In this case, the reflexive pronoun is immediately placed after the subject.

48) Daniel himself cooked the dinner.

In spoken English, it is placed at the end of the sentence. The reflexive pronoun is used after the preposition by to express the meaning alone.

49) I can't lift this box of books by myself. Will you help me? (Salas, 1998, pp. 40-41)

\subsubsection{Possessive Pronouns}

Possessive pronouns point out to the person who possesses a thing, which can be grouped into two sets. The first is the strong set because the possessive pronouns have an independent function (Alexander, 1990, p. 60) whereas the second is the weak because the pronouns have determinative function. The possessive pronouns are used with the word own to express the meaning of force. They have an emphatic meaning.

50) This book doesn't belong to the library. It is my own copy.

The meaning of force can be emphasized by the use of own with the adverb very.

51) Do you like this cake? It's my very own recipe (a recipe I made up myself) (Quirk et al., 1985, p. 363).

On the opposite, the independent pronouns cannot be used with the emphatic determinative own. The meaning of formality is expressed by the use of a determiner pronoun with a gerund which is also preceded either by a determiner pronoun or an object. Both of them are correct and the meaning is different on the basis of semantic considerations.

52a) I didn't like them singing.

b) I didn't like their singing.

In (52 a), it refers to the fact, and in (52 b), it refers to the quality (Penston, 2005, pp. 43-44).

\subsubsection{Reciprocal Pronouns}

Reciprocal pronouns express a two-way reflexive relationship. They indicate the meaning of reciprocity between two or more than two persons (Quirk et al., 1985, p. 364).

\subsubsection{Demonstrative Pronouns}

Demonstrative pronouns are considered as deictic expressions. Semantically, they have distal and proximal meanings. It means that they refer to something either nearer or far away from the speaker.

Pragmatically, they are used to focus the hearer's attention on locations or times in the speech situation. They are not personal, so their use of the demonstrative pronouns without being followed by a noun is considered as a kind of slighting. 
53) Is she going to marry that?

The demonstrative pronouns depend on the context in their interpretation. It means that it is difficult to know their reference. They are divided into: personal, spatial, temporal, social and discourse deixis. (Diessel, 1999, p. 2).

\subsubsection{Relative Pronouns}

The semantic relation of the relative pronouns is the distinction between restrictive and non-restrictive relative clauses. The restrictive relative clause is used to modify the head word in the main clause and give a definition of the antecedent word. It makes the reference of the antecedent clear (Quirk et el., 1985, p. 366).

The non-restrictive relative clause is used to describe the antecedent word. Sometimes the relative clause is used to modify not only the head word of the main clause, but the whole clause. In this case, it is called sentential relative clause.

54) John continues to respect his boss, which is unusual (Kennedy, 2003, pp. 279-280).

\subsubsection{Interrogative Pronouns}

Interrogative pronouns are used to know the identity of someone or something which are used in making questions to get information. They are invariable for gender and number. The pronouns which and what have definite and indefinite meanings. The interrogative pronouns can immediately be followed by a noun which is asked about. In this case, they are called interrogative determiners. The interrogative pronouns can be used in an emphatic function by using ever (Berk, 1999, p. 93).

\subsubsection{Indefinite Pronouns}

The element of the definiteness is missed in the indefinite pronouns which are used to refer to people or things whose identity is unknown. They are used as specifiers. It implies that they have the meaning of pointing out to something and they are considered as quantifiers because they indicate the presence or absence of the quantity (Quirk et al., 1985, p. 376).

The indefinite pronoun one has a generic meaning. It can be used as an impersonal pronoun. The use of the pronoun one makes the speaker uncommitted for personal experiences:

55) One should not always be polite (Azar, 2000, p. 41).

\subsubsection{Types of Pronouns in Arabic}

In Arabic, the division of pronouns can also be done according to the meaning and usage. They are divided into:

\subsubsection{Personal Pronouns}

\section{1) First Person Pronouns}

First person pronouns are called the pronouns of presence because the speaker is present at the time of using these pronouns which are:

a) The pronouns (ana), (iyyaya), and (taa?) have a reference about the person who is talking about himself.

56) ana 9araftu wajiby.

I knew my duty (Al-Ghalayny, 2005, p. 83).

b) The pronouns (iyyana), (na), (naHnu) express duality and plurality. The pronoun (naHnu) does not mean that it is the plural of (ana) and the difference is not a matter of singularity and plurality, but it is the combination of (ana), (anta) and (huwa).

c) The pronoun (yaa?) is an attached pronoun which refers to the person who is talking about himself (Abd-Altawab, 1992, p. 77).

\section{2) Second Person Pronouns}

The second person pronouns are called the pronouns of presence because the second person or the addressee should also be present at the moment of speaking. They are:

a) The pronouns (anta), (iyyaka), and (ka) are used to indicate singular masculine.

b) The pronouns (anti), (iyyaki), and (ki) refer to a singular feminine person.

c) The pronouns (iyyakuma) and (antuma) are used to refer to duality either feminine or masculine.

d) The pronouns (iyaakum) and (antum) refer to plural masculine. 
e) The pronouns (iyyakunna) and (antunna) are used with plural feminine (Fawziya, 2010, p. 7).

3) Third Person Pronouns

Third Person pronouns have the meaning of pointing that refers to an absent person:

a) The pronouns (huwa), (iyyahu), (haa?) are used with a singular masculine person.

b) The pronouns (hiya), (iyaha) refer to a feminine person.

c) The pronouns (iyyahuma) and (huma) denote the duality whether they are used with feminine or masculine.

d) The pronouns (iyyahum) and (hum) refer to plural masculine third persons.

e) The pronouns (iyyahunna) and (hunna) are used with plural feminine (Al-Farakh, pp. 41-43).

4) There are pronouns that can denote both second and third person.

a) (alif of duality), b) (waw of plurality), and c) (nuun of femininity)

\subsubsection{Possessive Pronouns}

Possessive pronouns have a semantic function to indicate the meaning of possession. They are attached pronouns which are considered as bound suffixes because they attach to a noun and depend on it in its occurrence. These pronouns are:

a) Possessive first person pronouns: (yaa?) (na).

b) Possessive second person pronouns: (ka), (kuma), and (kum).

c) Possessive third person pronouns: (haa?), (huma), (hum), (hunna) (Jiyad, 2017, p. 10).

\subsubsection{Pronouns of Concern and Separation}

There are other two pronouns that are used semantically and pragmatically which are:

\section{1) The Pronoun of Concern}

The pronoun of concern is connected with third person pronouns. They are used at the beginning of a declarative sentence. If the pronoun is masculine, it is called the pronoun of concern but it is called the pronoun of story if it is used with a feminine pronoun. It always occurs in the singular form which is used with (Dhanna) and its sisters. In addition, it is used to greaten the story or event and in situations that require eloquence. The pronoun of concern can either be a detached, an attached or an implicit pronoun (Al-9alawy, 1992, p. 116).

\section{2) The Pronoun of Separation}

The pronoun of separation is used to separate the main part of the nominal sentence in order to ensure its meaning. It occurs between the subject and the predicate. There are conditions under which this pronoun is used:

(1) One of the nominative detached pronouns should be a pronoun of separation.

(2) It occurs between two definite units.

(3) That pronoun and the preceding noun should be the same in number and gender.

(4) There should not be any connection between the subject and the predicate.

\subsubsection{Emphatic Function of Pronouns}

The emphatic function is an important part that can be dealt with within pragmatics. One of the types of emphasis is verbal which is the recurrence of the previous form by itself or by another form. The reason for using pronouns to have an emphatic function is to attract the hearer's attention and to ensure that what is said is correct. The pronouns that are used to do this function are: emphasis of the detached pronouns, emphasis of the attached pronouns, and emphasis of the implicit pronouns.

\subsubsection{Deixis}

Pronouns do not have a meaning by themselves. They have a pragmatic function of which speakers make use in communicating with others.

Deixis is a linguistic sign which depends on the context in order to know its reference. It has many types and personal deixis is one of those types which should depend on matching the reference with reality or what is called truth condition speech (sharT alSidiq) in order to decide that these pronouns are considered as deictic. Personal deixis consists of first, second, and third person pronouns (Al-Shahry, 2004, pp. 286-287). 


\section{i. First Person Pronouns}

The first-person pronoun (ana) reflects pride and courage or when someone has the pride of doing something. The pronoun (naHnu) refers to masculine and feminine so it removes any kind of discrimination between males and females. It also expresses strategic solidarity.

The attached pronouns (nuun) and (na) are used to express strategic solidarity and they replace the pronoun (naHnu). Furthermore, the attached pronoun (na) is sometimes found in contexts full of sympathy. It is sometimes used to refer to (antum) which is second person pronoun for plural (Al-tamiimy, 2004, pp. 321-322).

ii. Second Person Pronouns

Personal deixis includes second person pronouns which are used to direct the speech to the addressee. It also has the power of presence.

Collaborative anta consists of (anta) second pronoun for singular and (antum) second pronoun for plural. The pronoun (anta) is used when people are socially close to each other. It is used when people occupy the same social rank like children, friends and so on. It is also used when someone is talking to a new or an unfamiliar person. The pronoun (anta) is also a way to express strategic solidarity to show that people share the same aims. In addition, it is mentioned in situations in which someone expresses his/her admiration towards something or someone so it is a matter of praising.

When there are no close relationships, the pronoun (antum) is used in relations in which there is a kind of respect and social dimension.

Pronouns, whether they are attached or detached, can be used with each other in the same sentence referring to the same reference in order to express emphasis (Al-Shahry, 2004, p. 300).

\section{iii. Third Person Pronouns}

Third person pronouns are always considered as deictic expressions because they should be interpreted using the context, so they need a reference to interpret their meaning (Al-Hamad \& Al-Zu9by, 1993, p. 87).

\section{Method}

This study is descriptive, analytic and contrastive. It means that a full comprehensive and detailed description with analysis for pronouns are given in both languages, followed by a comparison made. The procedures followed in carrying out this study are shedding light on pronouns in English and then in Arabic in terms of definitions, explaining the syntactic, semantic, and pragmatic aspects. The information about pronouns in Arabic is translated into English. Examples are written in Arabic Alphapetical Symbols and then they are translated into English. Al-Mawrid and Expression Dictionary of Modern Linguistics are used in the translation of this study. The last step is showing a number of similarities and differences through the comparison made between the two languages.

\section{Results}

The study stems from the very general fact that languages can be contrasted. So it is hypothesized that English and Arabic are similar to each other in terms of syntactic, semantic, and pragmatic aspects of pronouns. After one-year research, this hypothesis is accepted. Then, the present study hypothesizes that such a topic which is pronouns exists in both languages which is also verified by the two researchers.

In addition, this study includes another hypothesis which is that there are some points of similarity and difference between the two languages, and the differences outweigh similarities like other studies in the contrastive analysis field. But the last hypothesis is refuted since that long research discovers the opposite which is there are some points of similarity and difference between English and Arabic, but the similarities are more than the differences in number.

\section{Conclusions}

There are some similarities and differences between pronouns in English and Arabic.

\subsection{The Similarities}

Pronouns as a grammatical topic exist in both languages. Pronouns are defined as one of the parts of speech. They are closed system items. It means that they are fixed in number and new words cannot be added. They are used as substitutes of noun phrases, which are not derived. They have a constant form.

Pronouns occur in the nominative, accusative and prepositional cases. In Arabic, the same pronoun can be used in the nominative, accusative and prepositional cases such as the pronoun (na). There are pronouns that share the 
accusative and the prepositional cases. These pronouns are (first person yaa?), (second person kaf), and (third person haa?) which are similar to English pronouns that appear in the three cases which are you and $i t$. There are pronouns that can be used in the accusative and prepositional cases like me, us, him, her, and them.

Furthermore, in both languages, there are certain pronouns that can be used to refer to feminine or masculine such as (ana), (naHnu), (huma), (antum which is added to a verb), (antuma). The first $I$ and we, second you, there are also pronouns that are gender neutral like the third plural pronoun they. There are also specific pronouns that indicate singularity and others that denote plurality.

The purpose of using the pronouns is to avoid repeating the noun phrase and they are used to hide the explicit noun. They help the writer or the speaker not to state his name and be kept away from unnecessary reiteration. This makes the reference of the pronoun clear.

Pronouns are definite and used to refer to the first, second, and third persons. The first and second are known and have a limited reference which are called the pronouns of presence because the speaker and the addressee are present at the time of speaking, while the third person pronouns cannot be used only when the addressees know their reference or to which they refer. Pronouns can be used to have personal and non-personal references. Because pronouns are indeclinable, the pronouns have a reference to number formula, but they cannot be dual or plural.

In addition, there are certain pronouns that cannot be used at the beginning of the sentence like the attached pronouns in Arabic and the reflexive pronouns in English. Pronouns can have an emphatic function. The reflexive pronouns can be used to express emphasis if they are immediately used after the subject. In Arabic it can be expressed by detached, attached, and implicit pronouns. The meaning of reflexivity can be expressed in both languages and each language has a certain pronoun to perform this function. In both languages, the reflexive pronouns occur in the accusative and prepositional cases. They never appear in the nominative case.

Pronouns are dealt with syntactically, semantically, and pragmatically. More than one pronoun can be used in the same sentence to refer to the same person or thing. Pronouns in a subject position cannot be deleted because the subject is considered as the main part of the sentence. Pronouns cannot be modified by determiners because they are considered as one of the definite elements. So, they do not need a determiner or an adjective to identify them. Pronouns have agreement in case, person, number, and gender with the verb or with the noun for which they substitute. Pronouns are used to express the meaning of possession.

It is noted that there is a kind of dominance relationship among the first, second, and third person pronouns. It means that the first person pronouns are more definite than the second and the third ones. Also, the first and the second are called the pronouns of presence because the speaker or addressee is found at the moment of using them. The second is more definite than the third. Furthermore, the third person pronouns are not definite by themselves, but they have a reference to a noun in order to understand their meanings.

The demonstrative pronouns are deictic expressions which have a pragmatic function and their reference depends on the context of situation in order to know their reference. They do not have a meaning by themselves. Similarly, the first-person pronoun (naHnu) can be used as a deictic expression. It has a pragmatic function. It refers to a single person which can be used to refer to the second person (anta) which does not refer to the speaker. The pronoun we cannot be used to refer to the speaker, but to the addressee. It can be used to have a reference to the second person you. The same is with the first-person pronoun (na) which is an attached pronoun. It can be used to replace the detached pronoun (naHnu). It has a pragmatic function which is one of the personal deixis. It does not refer to the speaker, but it is used to refer to the addressee or the second person. It is used in contexts which are full of passion such as in educational context between the teacher and his student. The pronoun we also denotes the same function that can be used to refer not to the speaker but to the addressee. It is also found in the educational context and in the relation between the doctor and the patient. The use of this pronoun indicates that the doctor shares the problem with his patient. In the educational context, the teacher uses this pronoun to instruct his student without the need to impose his authority.

There is a pronoun which is called the pronoun of concern which is used in its singular form. It has a pragmatic function that is used to greaten the story or event. It is called the pronoun of concern if it is masculine or the pronoun of story if it is feminine. It requires the eloquence in its use because the existence of vagueness and ambiguity in using such a pronoun gives people the desire to understand it. It is similar in a slightly limited way to the pronoun it which can be used to put an emphasis on the noun phrase that comes after it. It is called anticipatory it.

The implicit pronoun is found in both languages. In English, it exists in the command sentences especially with 
the subject you. The addressee is found at the moment of speaking, so it is not necessary to use the pronoun you.

\subsection{The Differences}

Concerning number and gender, in Arabic, there are pronouns which are used to refer to singularity, duality and plurality, while in English, there are only singularity and plurality.

In English, the second person pronoun you is used for both feminine and masculine. But in Arabic, the pronoun (anta), (iyaaka) and (ka) are used for a singular masculine person, (anti), (iyyaki) and (ki) are used for a singular feminine person, (antum) and (iyyakum) denote plural masculine persons, (antunna) and (iyyakunna) indicate plural feminine persons. In English, the number of the second person pronouns consists of only the pronoun you which is used to refer to either singularity and plurality, or feminine and masculine persons. In Arabic, the number of the second person pronouns are (anta) (iyaaka) (ka), (anti) (iyaaki) (ki), (antum) (iyaakum), (antumaa) (iyaakumaa), (antunna) and (iyaakunna).

Then it should be known that the number of pronouns is different between the two languages. Each language has its own number of pronouns. There are pronouns in English that do not have their counterparts in Arabic and the opposite is true.

Regarding types of pronouns, in Arabic, pronouns are divided into attached and detached pronouns and it is possible to have more than one attached pronoun in the same word but in English, there are no attached pronouns only detached. In Arabic, the attached pronouns occur in the nominative, accusative and prepositional cases. The detached pronouns occur in the nominative and accusative cases only. Thus, the nominative and accusative cases can either be detached or attached and the prepositional case is only attached pronouns. In English, the nominative, accusative and the prepositional cases are found only with detached pronouns. In addition, in Arabic, it is possible to have three pronouns which are used in the same sentence to refer to the same person. These pronouns can be detached and attached. In English, it is possible to have three pronouns to refer to the person, but all these pronouns are detached ones.

In Arabic, using the attached pronouns is preferred than the detached ones. But if it is necessary to use the detached pronouns, they will be used. The reason for this is that the attached pronouns are considered as more abbreviated than the detached ones and the purpose of using the pronouns is for conciseness and avoiding ambiguity. In English, all the pronouns are used when there is a necessity for using them and there is no preference for using one type of pronouns rather than another.

In Arabic, there are pronouns that can be used as second and third person pronouns which are (alif of duality), (waaw of plurality) and (nuun of femininity). But in English, the second person pronoun you cannot occur as first or third person.

In English, there are interrogative pronouns which are used to ask for things or persons, but in Arabic there are no pronouns that correspond to this type of pronouns.

In Arabic, there are certain signs (Harakat) that are used with the pronouns such as (fatHa), (Dhamma), (kasra), and (skuun). The sign (Haraka) of the verb changes from one pronoun to another. But in English, there is no such a thing.

In terms of classifying pronouns, the pronouns are different in the two languages. In English, they are personal, possessive, reflexive, reciprocal, demonstrative, interrogative, relative, and definite which are studied syntactically, semantically and pragmatically while in Arabic, pronouns are syntactically divided in terms of explicit and implicit, number and type. Semantically and pragmatically, they are divided into personal pronouns which are first, second and third; the pronouns that have the meaning of possession; the pronouns of concern and separation; the role of pronouns in emphasis; and the role of Arabic deixis.

In Arabic, there are pronouns that attach to a noun to give the meaning of possession. These pronouns are first person possessive pronouns (yaa?), (na), second person possessive (ka), (kuma), (kum), (ki), (kun), and third person possessive (haa?), (huma), (hum), and (hunna). While in English, the meaning of possession is obtained by detached pronouns only.

Furthermore, in English, deixis which has a pragmatic function can be divided into personal, spatial, temporal, social, and discourse. In Arabic, deixis is limited to the personal pronouns: first, second, and third.

In English, the pronouns this, that, these, those are called demonstrative pronouns. They do not have a meaning by themselves because they depend on the context in which they are used. It means that they have a pragmatic function and in this case they are called deictic expressions. While in Arabic the words which have the meaning of pointing are called demonstrative nouns. They do not belong to the domain of Arabic pronouns. 
In Arabic, the reflexive construction is obtained in two ways. First, the connection of two attached pronouns to the same verb, will express the meaning of reflexivity. The verb is not an ordinary verb, it must be one of the inversion verbs such as (Dhana), (Hasiba), (khala), (za9ima), (faqad), (waJada), and (ra?a). The reflexive pronouns occur in the accusative and prepositional cases. Second, the reflexivity occurs with verbs other than the inversion verbs. In this case, the word (nafs) is borrowed and the pronoun which is attached to it is an object. The object pronoun which is attached to the word (nafs) together with the subject gives the meaning of reflexivity. In English, two detached pronouns the subject and the object can have a reflexive relationship. It is not restricted to certain verbs, but there are verbs that cannot be used in the reflexive constructions.

Pragmatically speaking, in English, the first-person pronoun we is used to denote the speaker either feminine or masculine. In Arabic, the pronoun (naHnu) which is a first-person pronoun has a pragmatic function. The gender in Arabic is divided into male and female. The female gender is put in a lower rank. That's why; the pronoun (naHnu) is used to eliminate this kind of discrimination between males and females.

In Arabic, the pronoun (anta) is used for a pragmatic purpose which is called a collaborative (anta). It has a reference either to (anta) or (antum). It is used among people who have socially close relationship, especially, when they have the same gender, nationality, kinship, shared value, social career, and continuous communication. It is also used among children, friends, family members, and close colleagues who have the same social rank. It can also express strategic solidarity which means the supporting between people who have the same aims such as in media. It is used to denote people in general such as in commercial advertisement. Thus, every person will think that the speech is directed to him/ her, but in English, the second person pronoun you can be used to refer to people in general and between friends, but the functions that are used by the pronoun (anta) are more than those used by the pronoun you.

This study also shows that there is no specific pronoun for non-personal things in Arabic, while in English, the pronouns they and $i t$ are used.

In Arabic, a pronoun may consist of one sound, but in English there is no such a pronoun.

\section{References}

Abd-Altawab, R. D. (1992). Grammar Development of Arabic Language. Egypt: Al-Khanjy Library.

Abu-AlFutu, H., \& Hussein, M. (1995). Emphatic Style in Holy Quran (1st ed.). Beirut: Lebanon Library.

Abu-Al-Makarim \& Ali wa Al-Mukhtar, M. (2007). Nominal Sentence (1st ed.). Egypt: Al-Mukhtar Organization for Publishing and Distribution.

Al-Hamad, A., \& Al-Zu9by, Y. (1993). Al-Wafy Lexicon in the Arabic Grammar Tools (2nd ed.). Jordan: Hope dar.

Al-Ra9iiny, M. (1990). Alkawakib alduriya-sharH alshykh Muhammad bin Ahmed bin 9abd albary al?hdal 9la mutamima al?jrumiya (1st ed.). Beirut. Organization of Cultural Books.

Al-9alawy, H. (1992). Amali Ibn-alshajary (1st ed.). Egypt: Al-Khanjy Library.

Al-Anbary, A. B. (1982). Al?inSaf fi Masail Alkhilaf bayna alnaHwyyiin wal Kufyyiin. Beirut: House of Thought.

Al-Andulusy, A.-H. (1998). ?irtishaf alDharb min lisan alarab. Egypt: Al-Khanjy library.

Al-Astrabady, M. (1978). shariH Al-RaDhy 9ala alkafiya. Beirut: Al-shuruuq Printing.

Al-Baghdady, A. (1996). Origins of Grammar (3rd ed.). Beirut: Message Organization.

Alexander, L. G. (1990). Longman English Grammar. London: Longman.

Al-Farakh, M. Z. (n.d.). Clarity in Rules and Parsing.

Al-Ghalayny, M. (2005). Arab Lessons Collector. Egypt: Speech House.

Al-Ghuriny, M. S. (2000). albahja almurDhiya. Al-SuyoTy explanation about Alfiyat Ibn-Malik (1st ed.). Egypt: Peace House.

Al-LaHyany, Z. (2002). Cases of pronouns with their Interpreters. Unpublished MA. Thesis, University of umalqura, Saudi Arab Kingdom.

Al-Laymuun, A. (2010). Emphasis Style in Books of Quran Parsing. MA. Thesis, Mu?ta University, Jordan.

Al-Mashharawy, H. (2012). The phenomenon of Reflexive pronoun in Arabic Language. Unpublished MA. Thesis, Ghaza: Islamic University. 
Al-Quuzy, D. (1981). Grammatical Expression. Its Origin, Development until the End of the Third Century. Saudi: Deanship of Library Matters in Riyadh University.

Al-Sa9ady, S. B. (2009). Implicit pronoun in Grammar Lesson. Unpublished Ph. D. Dissertation, University of umalqura, Saudi Arab Kingdom.

Al-Shahry, 9abd Al-hadi bin-Dhafir. (2004). Strategies of Speech (1st ed.). Beirut: Dar of United New Book.

Al-SuyoTy, J. (1983). AlmaTali9 alsa9iida. Alaskandariya: University dar.

Al-SuyoTy, J. (2001). ham 9 alhawami9 fi sharih aljawami9. Egypt: World Books.

Al-tamiimy, sa9ad Muhammad Ali. (2016). Personal Deixis in Nahij albalaGha. Magazine of College of Humanities, 47, 317-348.

Aniis, I. (1994). Language Secrets (7th ed.). Egypt: Egyptian Anjilo library.

Arts, B. (2001). English Syntax and Argumentation (2nd ed.). London: Macmillan.

Azar, B. S. (2000). Understanding and Using English Grammar (3rd ed.). London: Longman.

Azar, B. S., Barbara, F., \& Shelly, H. (2001). Understanding and Using English Grammar (3rd ed.). London: Longman.

Berk, L. M. (1999). English Syntax. Oxford: Oxford University Press.

Betti, M. J. (2007). Jokes in Iraq: A Study of Coherence and Cohesion. Journal of the College of Education-University of Wassit, 1(1), 399-411.

Biber, D. (1999). Longman Grammar of Spoken and Written English. London: Longman.

Borjars, K., \& Burridge, K. (2010). Introducing English Grammar (2nd ed.). London: Hodder Education.

Cruse, A. (2000). Meaning in Language. Oxford: Oxford University Press.

Diessel, H. (1999). Demonstratives, Forms, Functions and Grammaticalization. Amesterdam: John Benjamins Publishing Company. https://doi.org/10.1075/tsl.42

Eastwood, G. (1994). Oxford Guide to English Grammar. Oxford: Oxford University Press.

Eckesley, C. E. (1966). A Concise English Grammar for Foreign Students. London: Longman.

Fawziya, D. (2010). Arabic Pronouns: Concept and Function. Magazine of College of Arts and Social Science Humanities, 6, 1-16.

Givon, T. (1990). Syntax: A Functional-Typological Introduction. Amesterdam: John Benjamins Publishing Company.

Greenbaum, S., \& Nelson, G. (2002). An Introduction to English Grammar (2nd ed.). London: Longman.

Gucker, P. (1966). Essential English Grammar. New York: Dover Publications, Inc.

Halliday, M. A. K., \& Hasan, R. (1976). Cohesion in English. London: Longman.

Hewings, A., \& Hewings, M. (2005). Grammar and Context. New York. Routledge.

Ibn-9aqiil, B. A. A. (1997). Ibn-9aqiil explanation about Alfiyat Ibn-Malik (5th ed.). Beirut: Mountain dar.

Ibn-Abi-Al-Rabii9. (1968). The Simple in Al-Zujajy's Explanation (1st ed.). Beirut: Western Islamic dar.

Ibn-Aldahan, Abo-Mhammmad sa9iid bin Al-Mubarak. (1988). Seasons in Arabic. Jordan: Hope House.

Ibn-Faris. (1971). Language Standards (2nd ed.). Egypt: MusTafa Albaby Al-Halaby.

Ibn-Jinny, Abo-AlFatiH 9uthman. (1985). Al- Lami9 fi al?rabiya (2nd ed.). Beirut: World of books.

Ibn-Ya9iish, M. A. Y. (2001). Detailed Explanation (1st ed.). Beirut: Scientific Books dar.

Jespersen, O. (2006). Essentials of English grammar. London: Routledge.

Jiyad, M. (2017). A Hundred and One Rules in Arabic Grammar. Califorinia: Create space Publishing Independent Platform.

Kennedy, G. (2003). Structure and Meaning in English. London: Pearson London.

Kimball, L. B. (2010). English Grammar. New York: American Book Company.

Kroeger, P. R. (2005). Analyzing Grammar: An Introduction. Cambridge: Cambridge University Press. https://doi.org/10.1017/CBO9780511801679 
Leech, G., \& Svartvik, J. (2002). A Communicative Grammar of English (2nd ed.). London: Longman.

Levinson, S. C. (1983). Pragmatics. Oxford: Oxford University Press. https://doi.org/10.1017/CBO9780511813313

MuHammad, 9iSam Abdullah. (2014). The Role of Pronouns in Connection through MuHammad and Yousuf Suras. PH.D Dissertation, Sudan University for Science and Technology, Sudan.

Murphy, R. (2004). English Grammar in Use (3rd ed.). Cambridge: Cambridge University Press.

Nelson, G. (2001). English an Essential Grammar. New York: Routledge.

Obrecht, F. (1999). Minimum Essentials of English (2nd ed.). New York: Barron's Educational Series.

Penston, T. (2005). A Concise Grammar for English Language Teachers. Wicklow: TP Publications.

Quirk, R., \& Greenbaum, S. (1973). A University Grammar of English. London: Longman.

Quirk, R., Greenbaum, S., Leech, G., \& Svartvik, J. (1985). A Comprehensive Grammar of the English Language. England: London.

Radford, A. (2004). Minimalist Syntax: Exploring the Structure of English. Cambridge: Cambridge University Press. https://doi.org/10.1017/CBO9780511811319

Rodman, R., \& Hyams, N. (2007). An Introduction to Language. Belmont: Thomson Wadsworth.

Saeed, J. I. (2016). Semantics (4th ed.). Oxford: Wiley Black well.

Salas, F. H. (1998). Elements of English Grammar (2nd ed.). Madrid: Bubok.

Silva, M. N. (1998). Basic Grammar in many Voices. New York: NTC Publishing Group.

Stilman, A. (1997). Grammatically Correct. Ohio: Writer's Digest Books.

Warith, S., \& Mursy, H. (2013). Pronouns and their Morphological and Structural Characteristics in AlQiyama Sura. Unpublished MA. Thesis. Republic of Algerian Popular Democracy: University of AbdulraHman Mira-Bajaya.

Yule, G. (1996). Pragmatics. Oxford: Oxford University Press.

\section{Appendix A}

List of Arabic Alphabetical Symbols (Betti, 2007)

\begin{tabular}{lll}
\hline$?$ & ja?a & (He came) \\
a & ana & (I am) \\
aa & aaman & (He believed) \\
b & balady & (my country) \\
t & kataba & (He wrote) \\
th & mithal & (example) \\
j & wajiby & (my duty) \\
H & naHnu & (we are) \\
kh & fakhr & (pride) \\
d & aldar & (home) \\
D & Dahaba & (He went) \\
r & ikhtiyar & (choice) \\
z & zalali & (slippage) \\
s & darasa & (he studied) \\
Sh & sha9ira & (poet) \\
S & Sana9a & (They made) \\
Dh & Dhamiir & (pronoun) \\
T & nashiiT & (active) \\
Dh & Dhanna & (He thought) \\
9 & sa9iid & (happy) \\
Gh & Ghadara & (He left) \\
f & fi & (in) \\
q & Hadiqa & (garden) \\
k & taskut & (She stops speaking) \\
1 & albaba & (the door) \\
M & madrasa & (school) \\
\hline & &
\end{tabular}




\begin{tabular}{lll}
\hline $\mathrm{n}$ & nafs & (self) \\
$\mathrm{h}$ & huwa & (He is) \\
$\mathrm{W}$ & wajada & (He found) \\
$\mathrm{y}$ & ruqy & (He was promoted) \\
$\mathrm{u}$ & antuma & (You are) \\
$\mathrm{uu}$ & Sadiquun & (They are honest) \\
ii & alsamii9 & (the hearer) \\
\hline
\end{tabular}

\section{Copyrights}

Copyright for this article is retained by the author, with first publication rights granted to the journal.

This is an open-access article distributed under the terms and conditions of the Creative Commons Attribution license (http://creativecommons.org/licenses/by/4.0/). 